Supporting Information for:

\title{
Measurement of formation rates of secondary aerosol in the ambient urban atmosphere using a dual smog chamber system
}

\author{
Spiro D. Jorga ${ }^{\dagger}$, Christos Kaltsonoudis ${ }^{\dagger}$, Aikaterini Liangou ${ }^{\ddagger}$, and Spyros N. Pandis $s^{\dagger, *,, *}$ \\ †Department of Chemical Engineering, Carnegie Mellon University, Pittsburgh, PA 15213, USA \\ \#nstitute of Chemical Engineering Sciences, ICE-HT, Patras, GR-26504, Greece \\ ${ }^{\S}$ Department of Chemical Engineering, University of Patras, Patras, GR-26504, Greece \\ *Corresponding author: Department of Chemical Engineering, University of Patras, Patras, GR- \\ 26504, Greece (e-mail: spyros@ chemeng.upatras.gr)
}

This file contains 10 pages, 8 figures and 2 tables. 


\section{Comparison of SMPS and AMS average distributions}

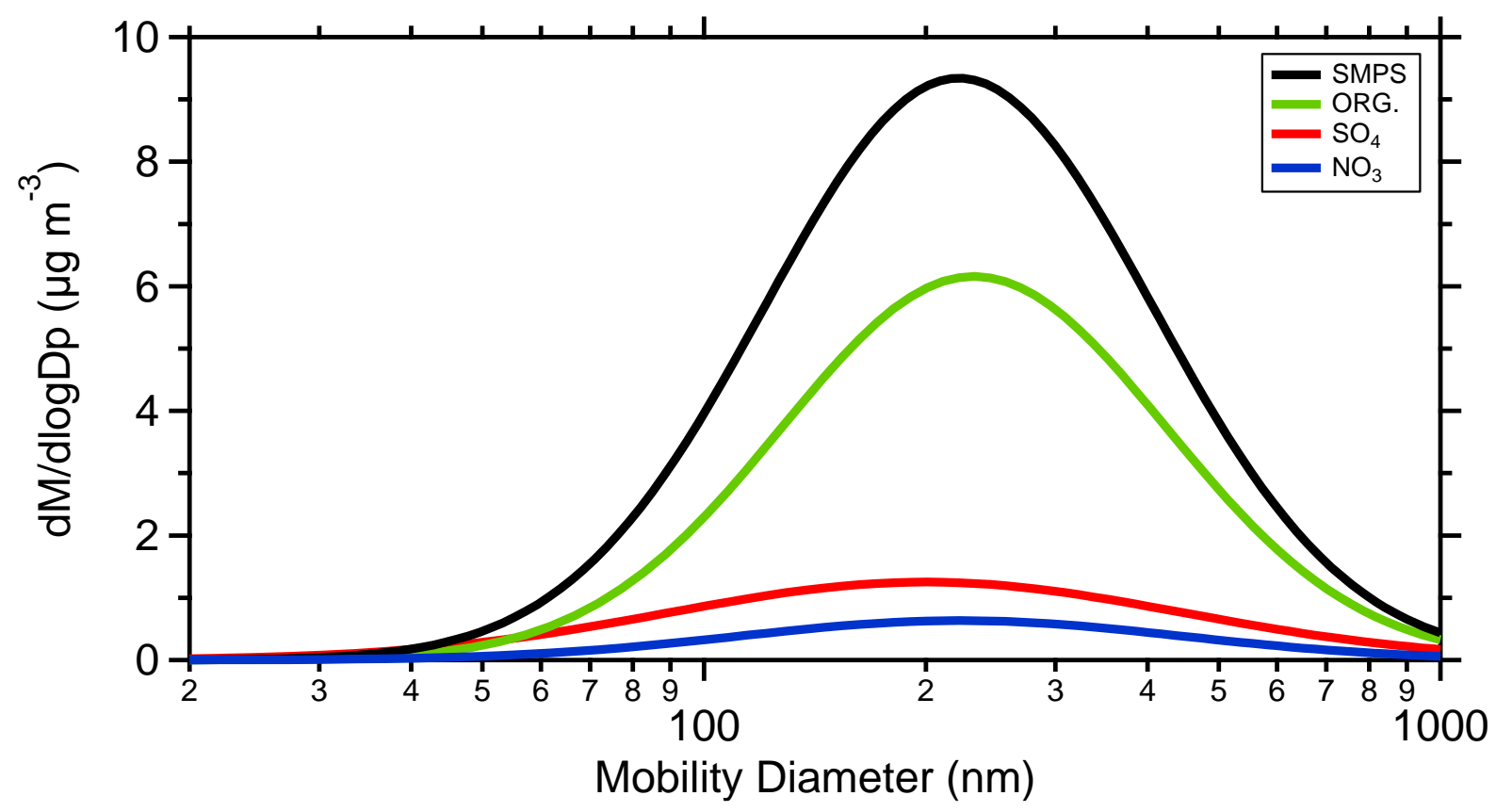

Figure S1: Comparison of the SMPS and major AMS components mass distributions in the perturbed chamber during Exp. 1. The distributions are corrected for both the collection efficiency and the particle density. Distributions are averaged over 30 minutes.

\section{Reduction of particle losses}

The portability of the dual chamber system provides the advantage of studying ambient atmospheric chemistry in different environments. Moving the system at a different location can induce charges on the Teflon walls, thus increasing the particle wall losses. Kaltsonoudis et al. ${ }^{\mathrm{S} 1}$ observed that the particle wall-loss rate constants increased almost by an order of magnitude for particles larger than $200 \mathrm{~nm}$, and even more for smaller particles after the chambers were moved to the field. Higher particle wall losses were also observed after significant maintenance work in the room in which the chamber was located ${ }^{\mathrm{S} 2}$. The chamber required months to return to its premaintenance condition.

We tested the ability of an ionizing fan (Dr Schneider PC, Model SL-001) to reduce any charges induced during the transport of the system. In a laboratory test, the chamber was handled by moving and touching the chamber walls, trying to imitate its handling during a field campaign. 
The electrostatic charges on the walls of the chamber were measured using an electrostatic charge meter (SIMCO ION, FMX-002). The measured electrostatic field at $1 \mathrm{~mm}$ from the chambers walls was on average $6 \mathrm{kV}$. After the disturbance, the particle wall-loss rate constant was measured by adding dry ammonium sulfate particles. Then, the chamber walls were swept using the ionizing fan for 15 minutes. The electrostatic field at $1 \mathrm{~mm}$ dropped to almost zero $\mathrm{V}$ after the use of the fan, and the particle wall-loss characterization was repeated. No additional air was added to the chamber. Figure S2 shows the coagulation-corrected particle wall-loss rate constants before and after the use of the ionizing fan. The particle wall-losses for particles above $150 \mathrm{~nm}$ were reduced by a factor of four returning to their normal levels of around $0.2 \mathrm{~h}^{-1}$. The test was repeated and similar results were obtained with the second chamber.

The use of the ionizing fan can help eliminate charges induced in the chambers during their deployment in the field. This procedure can also be implemented for indoor chamber facilities in order to decrease particle wall losses faster compared to natural charge dissipation e.g. after servicing/replacing the chamber. Reducing the particle wall losses in the chambers we can minimize the uncertainty introduced by the corrections for particle wall losses and allow the performance of longer experiments.

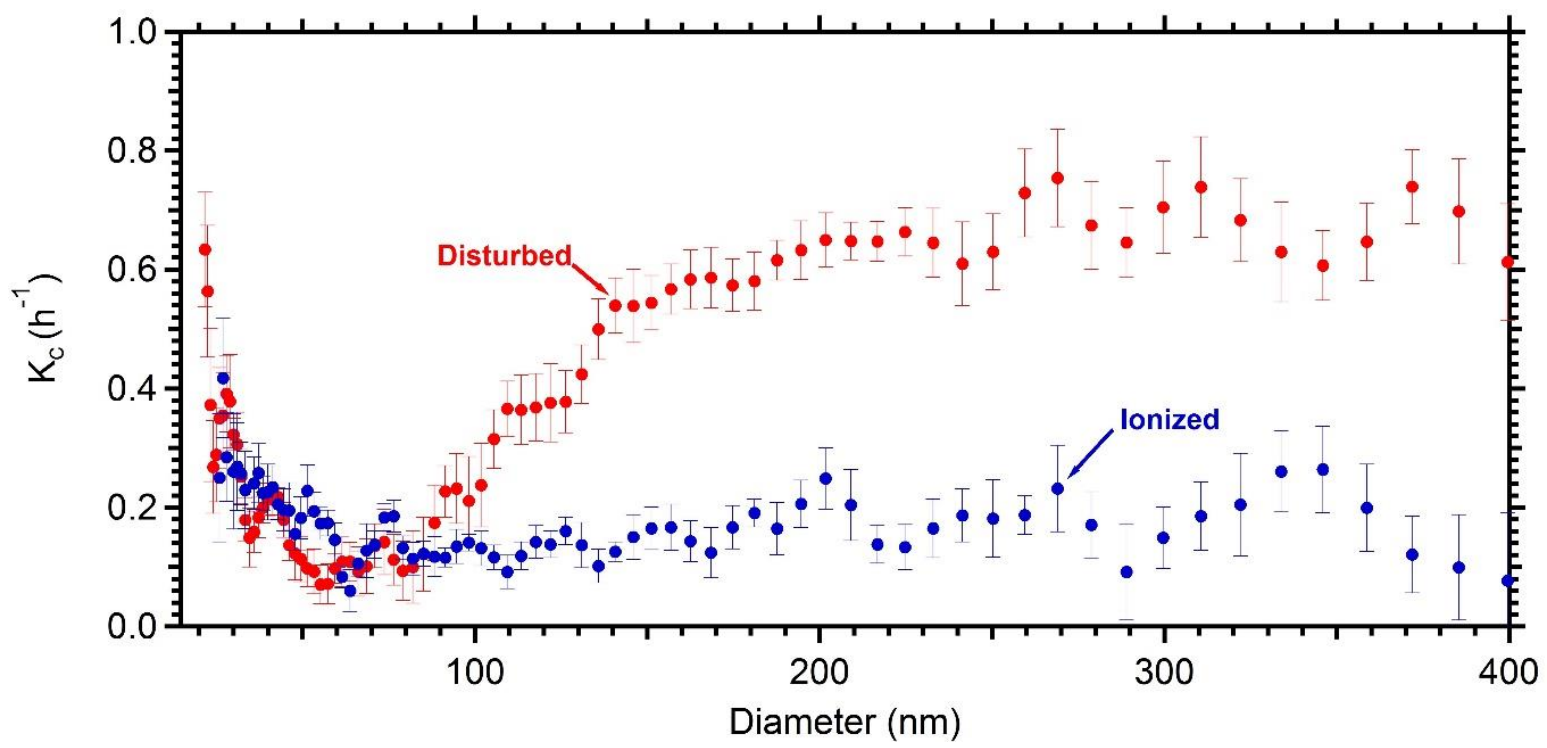

Figure S2. Coagulation-corrected particle wall-loss rate constants for the disturbed (red) and ionized (blue) chamber. The error bars represent the uncertainty associated with the particle wall rate constant. 


\section{OA enhancement as a function of $\mathrm{OH}$ exposure}

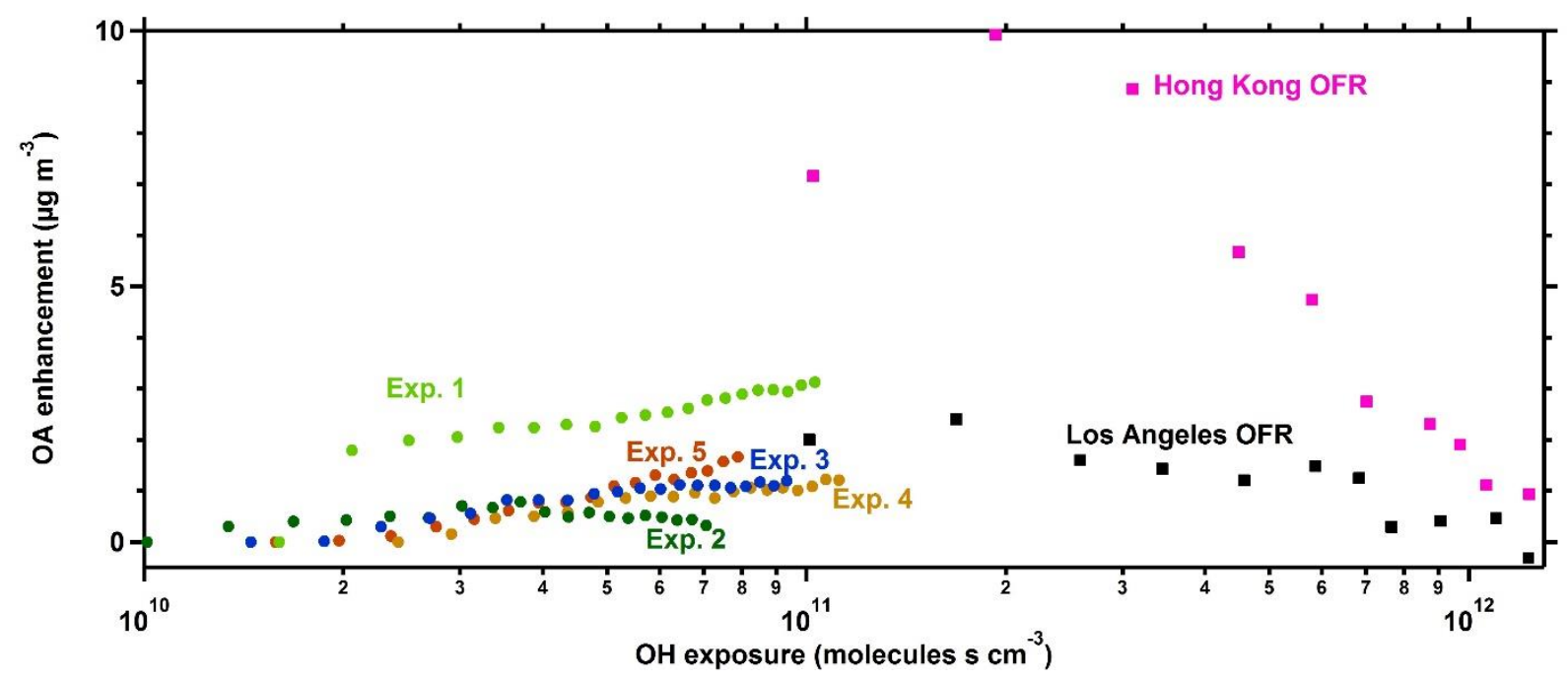

Figure S3: $\mathrm{OH}$ enhancement (final OA-initial OA) in the perturbation chambers for all the conducted experiments as a function of $\mathrm{OH}$ exposure. Also shown results of OFR measurements in Los Angeles ${ }^{\mathrm{S3}}$ (black squares) and Hong Kong ${ }^{\mathrm{S4}}$ (magenta squares).

\section{Calculation of organonitrates}

In order to calculate the fraction of nitrates attributed to organonitrates we used values of the ratio $\mathrm{NO}^{+} / \mathrm{NO}^{+}{ }_{2}(\mathrm{R})$ during a calibration of the AMS with ammonium nitrate. The fractional contribution of the organonitrates (ONit) to total nitrates (TotNit) can be calculated as:

$$
\frac{O N_{i t}}{\operatorname{TotN}_{i t}}=\frac{\left(R_{\text {mea }}-R_{c a l}\right)\left(1+R_{\text {ONit }}\right)}{\left(R_{O N i t}-R_{c a l}\right)\left(1+R_{\text {mea }}\right)}
$$

where $R_{\text {mea }}$ is the measured $R$ during the ambient sampling and $R_{\text {cal }}$ is the ratio of $m / z 30$ to $\mathrm{m} / z 46$ during $\mathrm{NH}_{4} \mathrm{NO}_{3}$ calibration. $R$ ONit is the $R$ derived from organonitrates, which in our case was the maximum $R$ (5.31) we observed during the ambient sampling. Using a $R_{\text {mea }}$ of 4.21 and $R_{\text {cal }}$ of 1.22 , approximately $90 \%$ of the measured nitrates were organic nitrates based on the method of Farmer et al. ${ }^{\mathrm{S} 5}$. 


\section{Estimation of the AMS spectrum of the SOA produced in the perturbed chamber}

The concentration of the produced SOA in the perturbed chamber was calculated assuming that the $\mathrm{OA}$ in the chamber is the sum of the remaining (after losses to the walls) initial OA and the produced SOA:

$$
O A(t)=O A_{\text {in }}(t)+S O A_{\text {prod }}(t)
$$

where $O A(\mathrm{t})$ is the measured $\mathrm{OA}$ (with no corrections) at time $t, O A_{\text {in }}(\mathrm{t})$ is the estimated initial $\mathrm{OA}$ remaining in the chamber at time $t$ and $S O A_{\text {prod }}(t)$ is the produced SOA that remains in the chamber at that time. We assume that the concentration of the initial OA just decays exponentially due to wall losses, thus:

$$
O A_{\text {in }}(t)=O A_{0} e^{-k t}
$$

with $\mathrm{OA}_{\mathrm{o}}$ being the initial OA concentration when the $\mathrm{UV}$ were turned on and $k$ is the average wall loss rate constant in the perturbed chamber for the size range of interest. Combing equations (2) and (3):

$$
S O A_{\text {prod }}(t)=O A(t)-O A_{0} e^{-k t}
$$

Figure S4 depicts the corresponding concentrations in the perturbed chamber for Exp. 1.

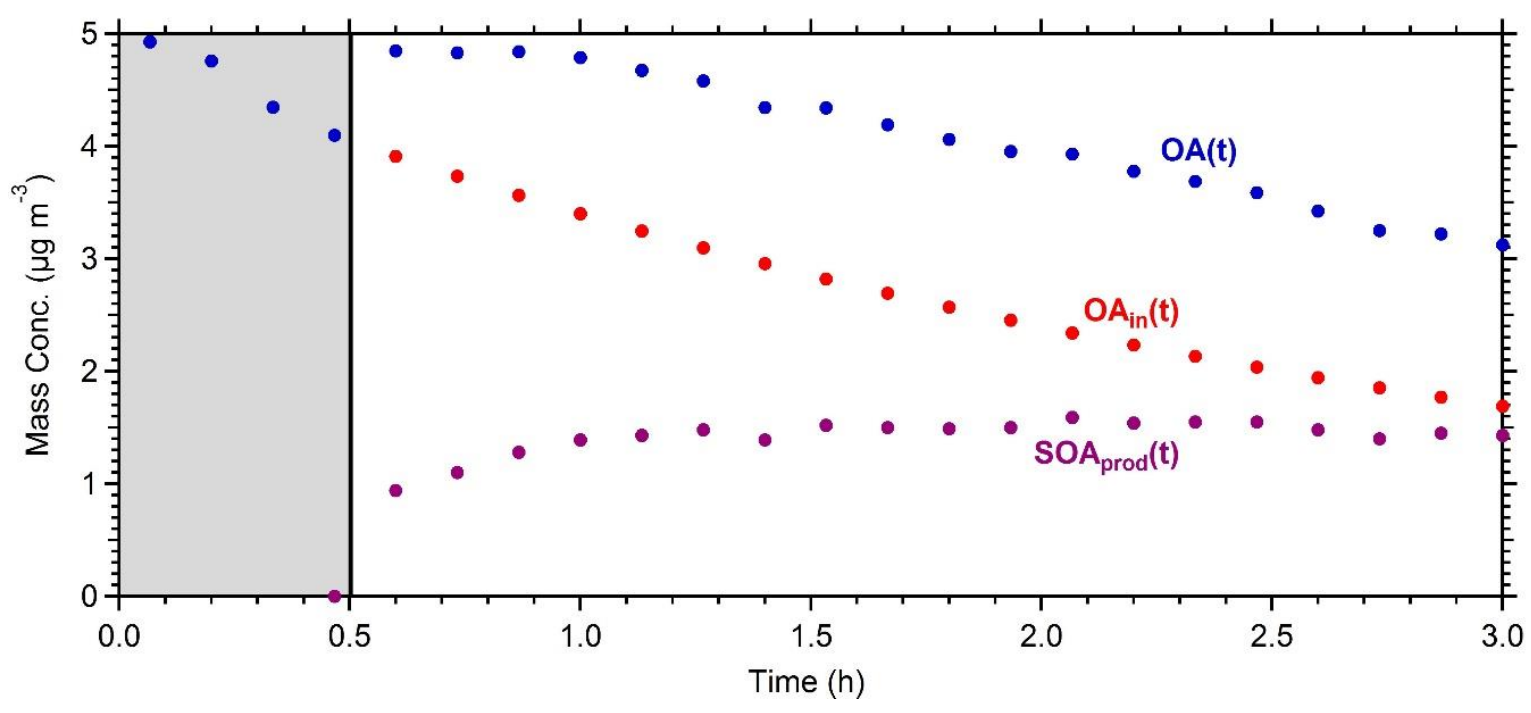

Figure S4: Mass concentration of the measured OA (blue line), the estimated OA (red line) and the produced SOA (purple line) in the perturbed chamber in Exp. 1. 
In order to estimate the mass spectrum of the produced SOA in the perturbed chamber we assume that the spectrum of the original OA remains unchanged, thus neglecting any heterogeneous reactions. From the corresponding mass balance:

$$
O A(t) M S(t)=O A_{0} e^{-k t} M S_{\text {in }}+\left(O A(t)-O A_{0} e^{-k t}\right) M S_{\text {prod }}
$$

where $M S(\mathrm{t}), M S_{\mathrm{in}}, M S_{\text {prod }}$ are the AMS spectra at time $t$, in the beginning of the experiment (before the UV lights were turned on) and of the produced SOA, respectively. An average spectrum $M S_{\text {fin }}$ is calculated averaging the mass spectra during a $30 \mathrm{~min}$ period in which the $S O A_{\text {prod }}(\mathrm{t})$ is relatively stable (Fig. S4) and the corresponding average concentration in the chamber is $O A_{\text {fin. }}$. The AMS spectrum of the produced SOA is then given by:

$$
M S_{\text {prod }}=\frac{O A_{\text {fin }} M S_{\text {fin }}-O A_{\mathrm{o}} e^{-k t} M S_{\text {in }}}{O A_{\text {fin }}-O A_{\mathrm{o}} e^{-k t}}
$$

The calculated AMS spectrum of the produced SOA for Exp. 1 in the perturbed chamber is shown in Figure S5.

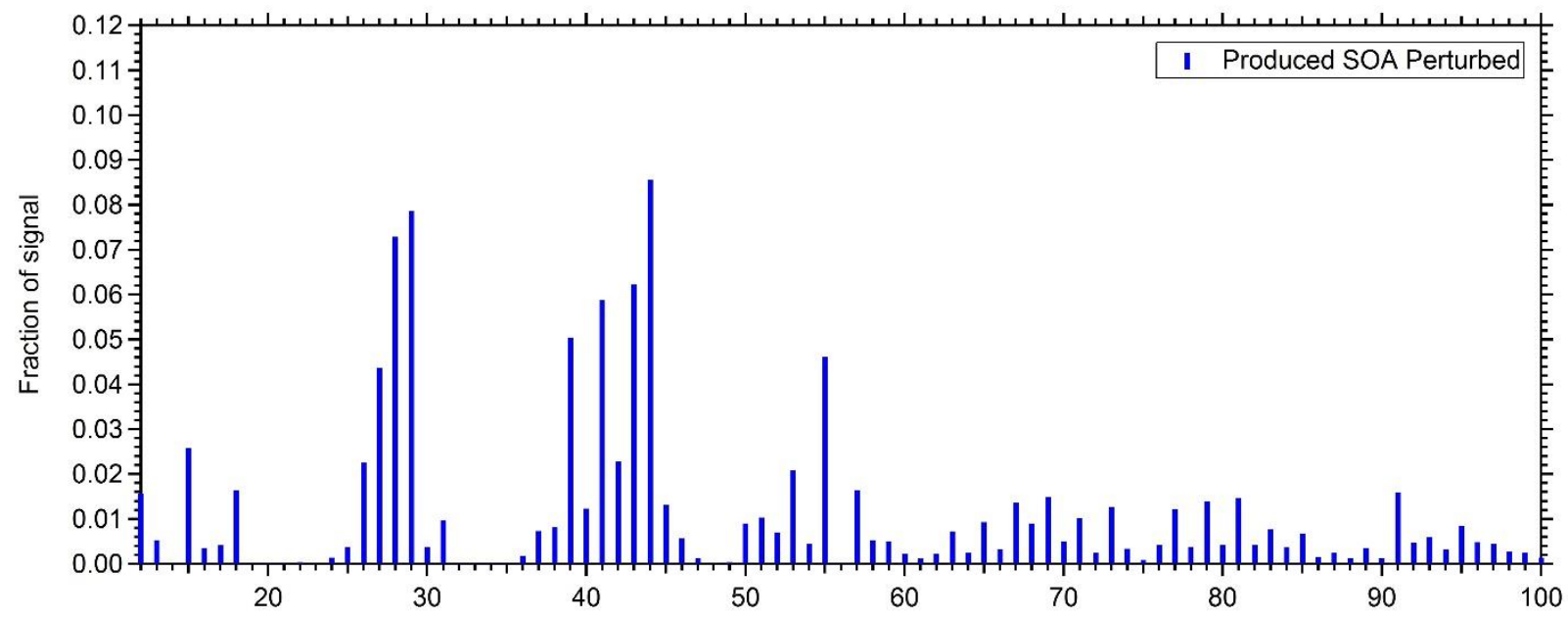

Figure S5: Estimated AMS spectrum of the SOA produced during Exp. 1 in the perturbed chamber. 


\section{Comparisons of AMS spectrum of produced SOA with other spectra}

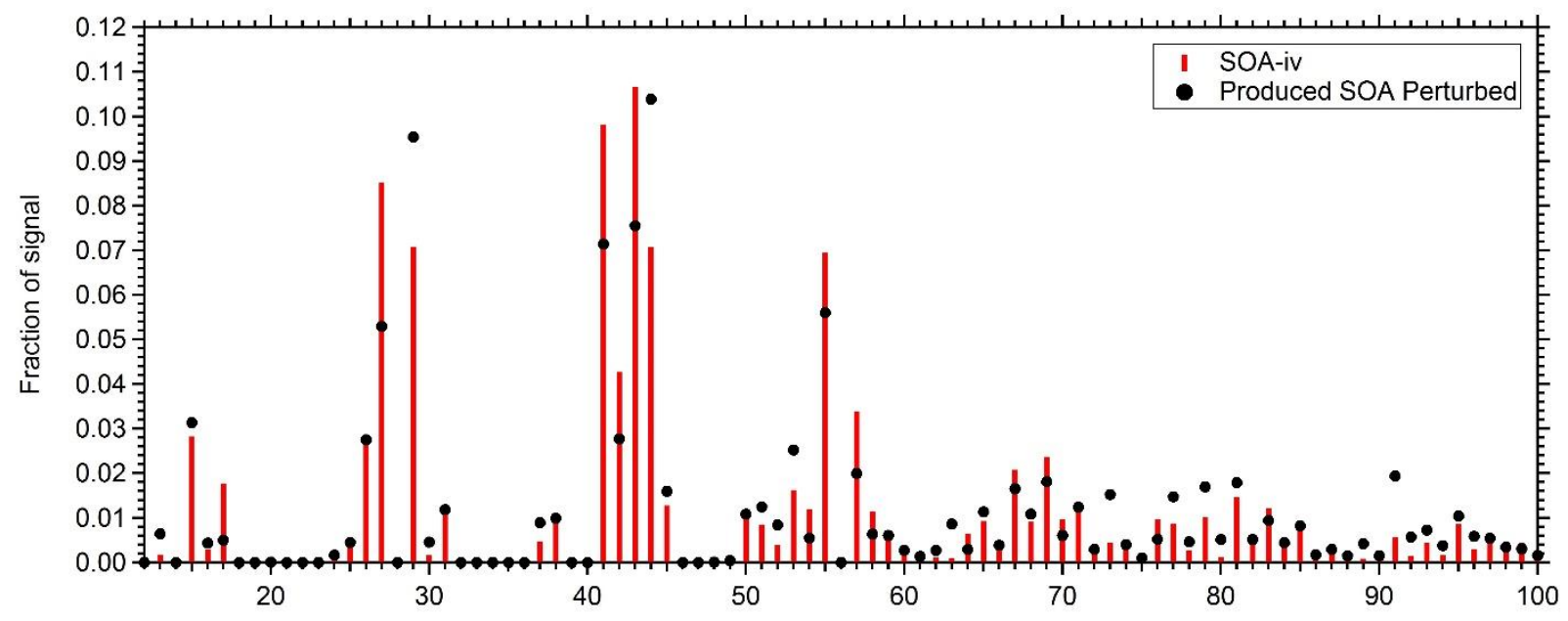

Figure S6: Comparison of the mass spectra of the produced SOA in the perturbed chamber during Exp. 1 (black circles) and the SOA from the mix of alkanes (red bars). The theta angle ${ }^{\mathrm{S} 6}$ was 20 degrees.

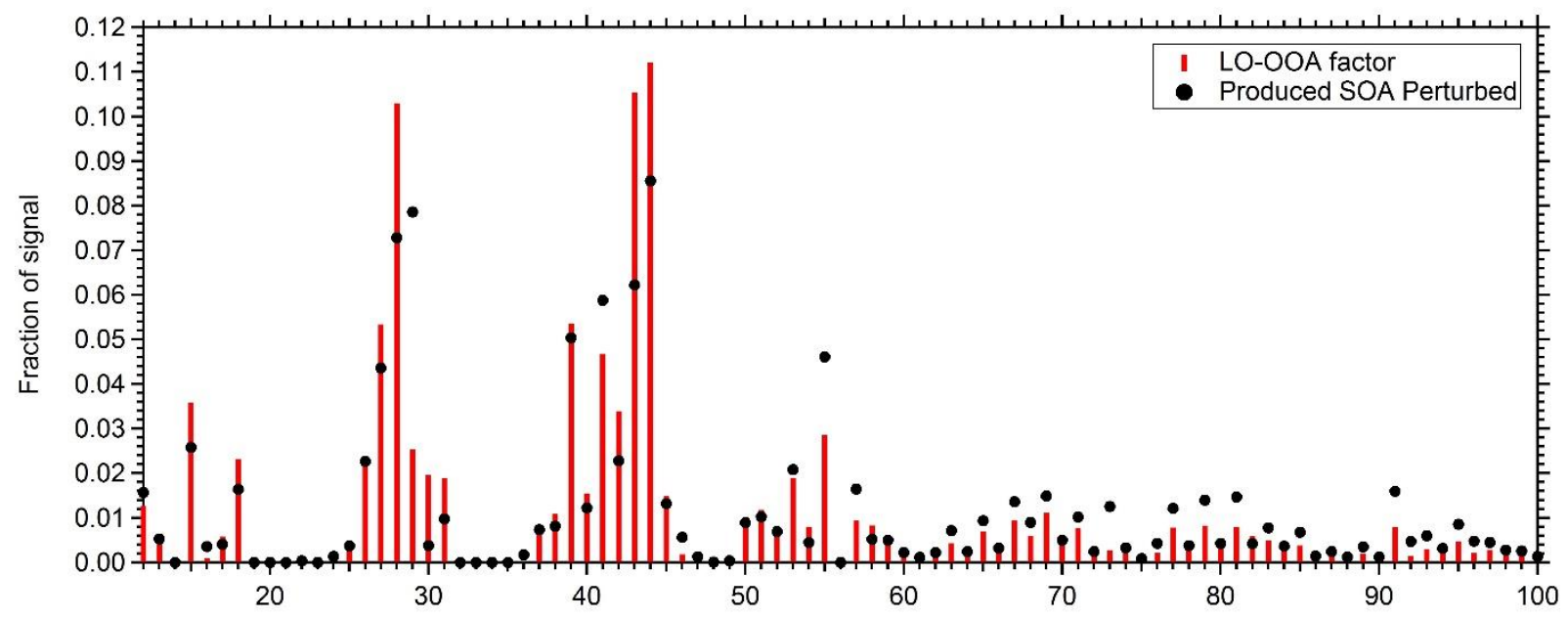

Figure S7: Comparison of the mass spectra of the produced SOA in the perturbed chamber during Exp. 1 (black circles) and the LO-OOA factor in Pittsburgh measurements ${ }^{\mathrm{S} 7}$ (red bars). The theta angle was 23 degrees. 


\section{VOC concentrations in the perturbed chamber}

a)

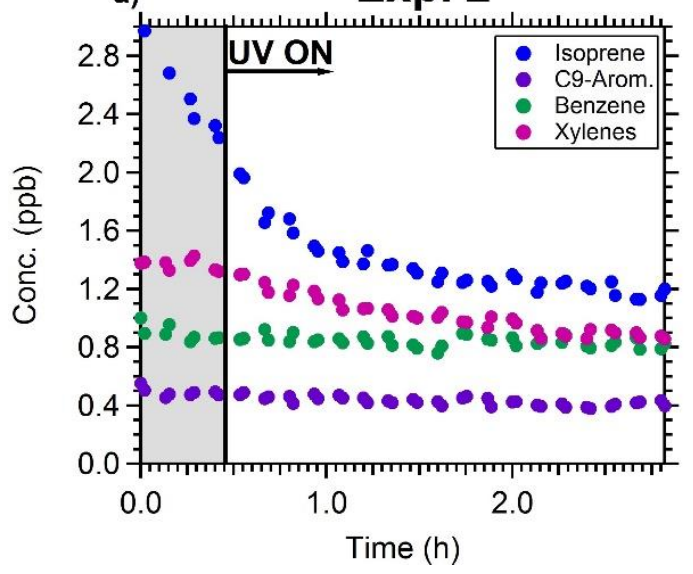

c)

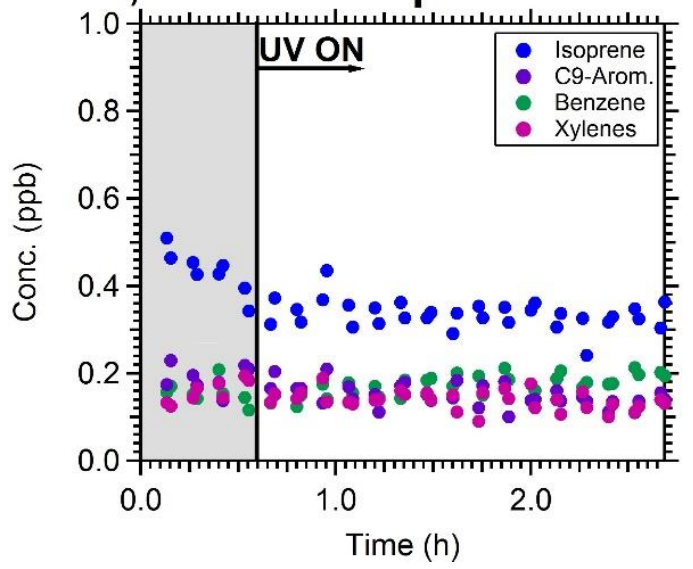

b)

Exp. 3

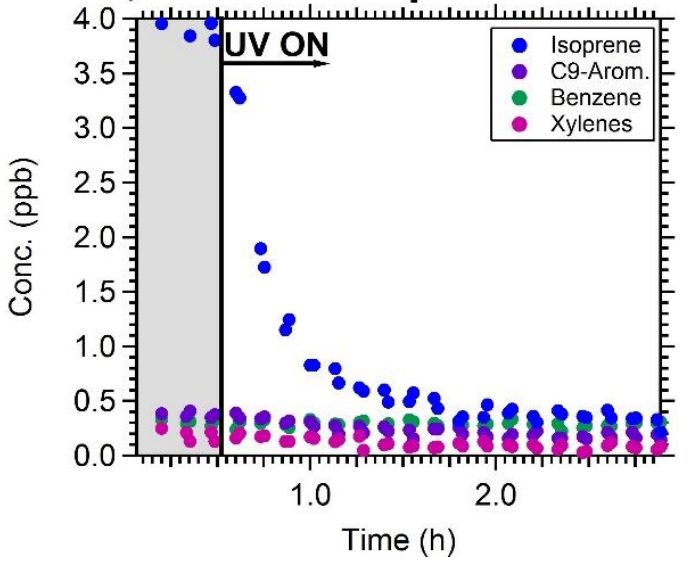

Exp. 5

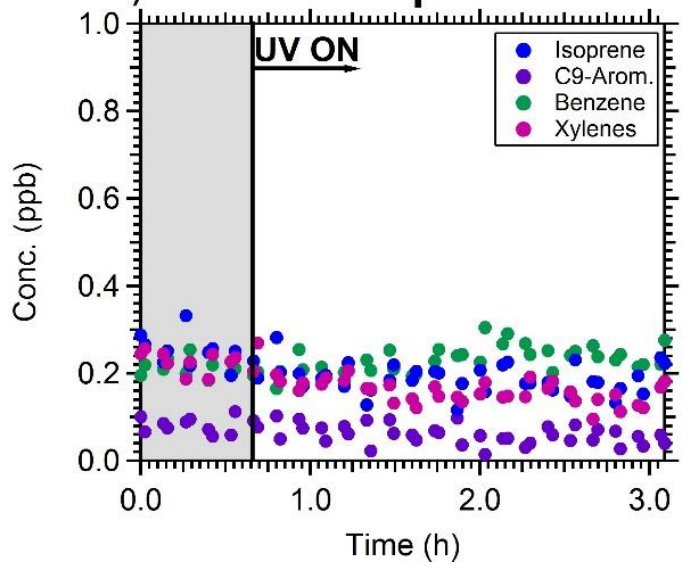

Figure S8: VOC concentrations as measured by the quadrupole PTR-MS in the remaining experiments conducted in the work, a) Exp. 2, b) Exp. 3, c) Exp. 4, and d) Exp. 5. 
Table S1: Additional information for the perturbation experiments

\begin{tabular}{cccccc}
\hline Exp. & $\begin{array}{c}\text { Month } \\
(\mathbf{2 0 1 8})\end{array}$ & $\begin{array}{c}\text { Ambient } \\
\mathbf{O}_{3} \\
(\mathrm{ppb})\end{array}$ & $\begin{array}{c}\text { Ambient } \\
\mathbf{N O}_{\mathbf{x}} \\
(\mathrm{ppb})\end{array}$ & Ambient PM $\mathbf{c}$ composition (\%) & $\begin{array}{c}\text { Time in the } \\
\text { beginning of } \\
\text { experiment }\end{array}$ \\
\hline 1 & July & 25 & 10 & Org. (80), Sulf. (16), Nitr. (1), Amm. (3) & $10: 00$ \\
2 & June & 25 & 5 & Org. (76), Sulf. (17), Nitr. (3), Amm. (4) & $12: 00$ \\
3 & May & 30 & 2 & Org. (79), Sulf. (15), Nitr. (3), Amm. (3) & $13: 00$ \\
4 & April & 35 & 4 & Org. (75), Sulf. (17), Nitr. (2), Amm. (6) & $12: 30$ \\
5 & February & 10 & 12 & Org. (77), Sulf. (14), Nitr. (2), Amm. (7) & $13: 00$ \\
\hline
\end{tabular}

Table S2: Comparison of the OA PMF factors identified in measurements in Pittsburgh ${ }^{\mathrm{S} 5}$ with the OA spectra in the perturbed chamber after the oxidation.

\begin{tabular}{ccc}
\hline Experiment & $\begin{array}{c}\text { Angle in degrees with less } \\
\text { oxidized OA in Pittsburgh }\end{array}$ & $\begin{array}{c}\text { Angle in degrees with more } \\
\text { oxidized OA in Pittsburgh }\end{array}$ \\
\hline July & 19 & 34 \\
June & 16 & 33 \\
May & 13 & 29 \\
April & 15 & 24 \\
February & 12 & 22 \\
\hline
\end{tabular}

\section{References}

(S1) Kaltsonoudis, C.; Jorga, S. D.; Louvaris, E.; Florou, K.; Pandis, S. N. A portable dual-smogchamber system for atmospheric aerosol field studies, Atmos. Meas. Tech. 2019, 12, 2733-2743.

(S2) Wang, N.; Jorga, S. D.; Pierce, J. R.; Donahue, N. M.; Pandis, S. N. Particle wall-loss correction methods in smog chamber experiments, Atmos. Meas. Tech. 2018, 11, 6577-6588.

(S3) Ortega, A. M.; Hayes, P. L.; Peng, Z.; Palm, B. B.; Hu, W.; Day, D. A.; Li, R.; Cubison, M. J.; Brune, W. H.; Graus, M.; Warneke, C.; Gilman, J. B.; Kuster, W. C.; de Gouw, J.; GutiérrezMontes, C.; Jimenez, J. L. Real-time measurements of secondary organic aerosol formation and aging from ambient air in an oxidation flow reactor in the Los Angeles area, Atmos. Chem. Phys. 2016, 16, 7411-7433. 
(S4) Liu, T.; Zhou, L.; Liu, Q.; Lee, B.P.; Yao, D.; Lu, H.; Lyu, X.; Guo, H.; Chan, C.K. Secondary organic aerosol formation from urban roadside air in Hong Kong. Environ. Sci. Technol. 2019, 53, 3001-3009.

(S5) Farmer, D. K.; Matsunaga, A.; Docherty, K. S.; Surratt, J. D.; Seinfeld, J. H.; Ziemann, P. J.; Jimenez, J. L. Response of an aerosol mass spectrometer to organonitrates and organosulfates and implications for atmospheric chemistry. Proc. Natl. Acad. Sci. U.S.A. 2010, 107, 6670-6675.

(S6) Kostenidou, E.; Lee, B.-H.; Engelhart, G. J.; Pierce, J. R.; and Pandis, S. N.: Mass spectra deconvolution of low, medium, and high volatility biogenic secondary organic aerosol, Environ. Sci. Technol. 2009, 43, 4884-4889.

(S7) Gu, P.; Li, H.Z.; Ye, Q.; Robinson, E.S.; Apte, J.S.; Robinson, A.L.; and Presto, A.A.: Intracity variability of particulate matter exposure is driven by carbonaceous sources and correlated with land-use variables. Environ. Sci. Technol. 2018, 52, 11545-11554. 